
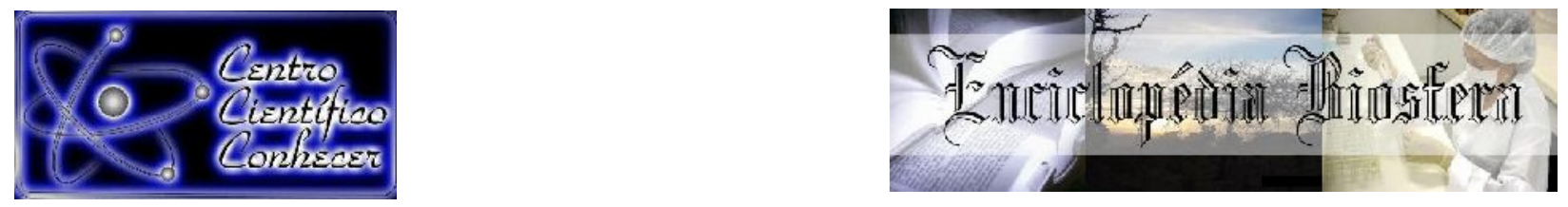

\title{
LETRAMENTO DIGITAL E ATIVIDADES ACADÊMICAS: UM ESTUDO DE CASO DE LICENCIANDOS QUE PARTICIPARAM DE EDITAIS DO PIBID/UFG
}

Paulo Henrique Santana de Oliveira ${ }^{1}$; Paulo Alexandre de Castro $^{2}$; Fábio Ricardo Mizuno Lemos ${ }^{3}$; Lucas Fagundes Vaz ${ }^{4}$; Maryele Lázara Rezende ${ }^{5}$

${ }^{1}$ Mestre em Gestão Organizacional pelo Programa de Pós-Graduação em Gestão Organizacional da Universidade Federal de Goiás, Catalão-GO, Brasil.

(paulhsdeoliveira@gmail.com)

${ }^{2}$ Doutor em Física pela Universidade de São Paulo - Instituto de Física de São Carlos, São Carlos-SP, Brasil.

${ }^{3}$ Doutor em Educação pela Universidade Federal de São Carlos, São Carlos-SP, Brasil.

${ }^{4}$ Especialista em Gestão de Tecnologia da Informação pela Universidade Candido Mendes, Goiânia-GO, Brasil.

${ }^{5}$ Mestra em Gestão Organizacional pelo Programa de Pós-Graduação em Gestão Organizacional da Universidade Federal de Goiás, Catalão-GO, Brasil.

\section{Recebido em: 06/04/2018 - Aprovado em: 10/06/2018 - Publicado em: 20/06/2018 DOI: 10.18677/EnciBio_2018A127}

\begin{abstract}
RESUMO
Avanços tecnológicos, sobretudo na área de Tecnologia da Informação e Comunicação, têm exigido o desenvolvimento da habilidade de lidar com equipamentos tecnológicos para se comunicar. Essa necessidade de aprender a ler e escrever no meio digital (letramento digital), estende-se ao contexto acadêmico. Entre as atividades que exigem esse conhecimento está a de submissão digital de propostas para editais de fomento ao ensino, pesquisa e extensão, como o do Programa Institucional de Bolsa de Iniciação à Docência (PIBID), que tem como foco o aprimoramento da formação de docentes para a educação básica. O objetivo deste trabalho foi investigar o letramento digital de estudantes licenciandos que participaram de editais do PIBID para o ano de 2016, na Universidade Federal de Goiás - Regional Catalão (UFG-RC). Para a coleta de dados, foi desenvolvido um questionário eletrônico contendo questões relacionadas com o nível de dificuldade. A análise dos dados se baseou em uma perspectiva quanti-qualitativa. Entre os resultados, 94\% informaram que acessam frequentemente a Internet; $60 \%$ dos estudantes tiveram "pouca dificuldade" de acesso ao sistema desenvolvido e a soma dos que apontaram que tiveram "muita dificuldade" ou "dificuldade" foi de $25 \%$. Sobre as informações/instruções disponibilizadas, 65\% responderam que "fizeram diferença" e $20 \%$ que "fizeram muita diferença". Foi possível constatar que apesar do domínio básico apresentado pela maioria, foi significativa a dificuldade de alguns. Tal realidade aponta para a necessidade de formação para o letramento digital, com o objetivo de estender e democratizar o acesso a fomentos acadêmicos.
\end{abstract}

PALAVRAS-CHAVE: letramento digital; sistema de submissão digital; usabilidade. 


\title{
DIGITAL LITERACY AND ACADEMIC ACTIVITIES: A STUDY CASE OF LICENSEES THAT PARTICIPATED IN EDICTS OF PIBID/UFG
}

\begin{abstract}
Technological advances, especially in the area of Information Technology and Communication, have required the development of the ability to handle technological equipment to communicate. This need to learn to read and write in the digital environment (digital literacy) extends to the academic context. Among the activities that require this knowledge is the digital submission of proposals for funding edicts to teaching, research and extension, such as the Institutional Scholarship Program for Initiation to Teaching (PIBID), which focuses on the improvement of teacher education for basic education. The objective of this study was to investigate the digital literacy of undergraduate students who participated in the PIBID notices for the year 2016, the Federal University of Goiás - Regional Catalão (UFG-RC). To collect data, it developed an electronic questionnaire containing questions related to the level of difficulty. Data analysis was based on a quantitative-qualitative perspective. Among the results, $94 \%$ reported that they frequently access the Internet; $60 \%$ of the students had "little difficulty" accessing the developed system and the sum of those who indicated that they had "much difficulty" or "difficulty" was $25 \%$. About the information/instructions made available, $65 \%$ answered that they "made a difference" and $20 \%$ "made a lot of difference". It was possible to observe that despite the basic mastery presented by the majority, the difficulty of a reasonable fraction (1/4) of the participants was significant. This reality points to the need for training for digital literacy, in order to extend and democratize access to academic programs.
\end{abstract}

KEYWORDS: digital literacy; digital submission system; usability.

\section{INTRODUÇÃO}

Avanços tecnológicos, sobretudo nas áreas de Tecnologia da Informação e Comunicação (TIC), são realidades presentes da sociedade atual. Acompanhar os avanços em todas as áreas do conhecimento foge ao controle individual, pois, em todo o Mundo a população é quase que diariamente bombardeada com o surgimento de novas tecnologias, além da evolução de tantas outras tecnologias como, por exemplo, o GPS (sistema de localização por satélite), smartphones, tablets, laptops entre outros (KIRCHOF, 2016). Nesse âmbito, muitas organizações têm buscado adaptar-se às TICs, pois as mesmas podem auxiliar na otimização de processos, gerando economia de tempo e em infraestrutura (VIEIRA, 2014; MENDONÇA; VARVAKIS, 2018).

No setor educacional, em alguns aspectos, a utilização de TICs ainda se mostra insipiente. Assim sendo, considerando o potencial das TICs em contribuir para a gestão de processos e de comunicação, tornando-a mais simples, prática e econômica, foi implementado um sistema on-line para atender a demanda de digitalização de inscrições em editais do Programa Institucional de Bolsa de Iniciação à Docência (PIBID) da Universidade Federal de Goiás - Regional Catalão (UFG-RC). A partir da implementação do sistema on-line, surgiu a necessidade de voltar a atenção ao letramento digital dos seus usuários. Letramento digital, segundo Xavier (2017, p. 2): 
[...] implica realizar práticas de leitura e escrita diferentes das formas tradicionais de letramento e alfabetização. Ser letrado digital pressupõe assumir mudanças nos modos de ler e escrever os códigos e sinais verbais e não-verbais, como imagens e desenhos, se compararmos às formas de leitura e escrita feitas no livro, até porque o suporte sobre o qual estão os textos digitais é a tela, também digital.

Em sua pesquisa Souza (2013), envolveu 53 participantes e testou dois ambientes virtuais de aprendizagem (AVAs), o TelEduc e o Moodle. Dessa pesquisa concluiu-se que cada aluno percebeu a ferramenta de uma forma diferente e buscou caminhos distintos para atingir seus objetivos, dado o ambiente complexo e adaptativo. Nesse sentido, é possível dizer que sempre poderá haver várias percepções e atuações diante das dificuldades de utilização de plataformas on-line.

Para Borges (2017, p. 281-282) "[...] a perspectiva do letramento incorpora à vida social dos sujeitos a necessidade de dominar as práticas de leitura e escrita com o risco de, não as dominando, encontrar dificuldade de identificação e integração àquela comunidade, sociedade". Deste modo, segundo o apontamento do autor os indivíduos que não dominam o letramento ou encontram dificuldade acabam por não se integrarem ao grupo social que estão inseridos. É válido ressaltar que o letramento digital vem sendo caracterizado por alguns termos, inclusive de origem da língua inglesa. Sobre isto, Borges (2017, p. 287) destaca que:

O letramento digital vem sendo comumente descrito e definido como um conjunto de habilidades técnicas, geralmente a partir de termos oriundos da língua inglesa, computer literacy, information literacy, eliteracy, network literacy e media literacy, entre as quais podemos destacar: letramento informacional, letramento computacional, letramento midiático, letramento multimidiático.

De acordo com Tiburzio (2014) é necessário levar em consideração que a inserção de usuários em ambientes acadêmicos com suporte digital depende das compreensões que têm de leitura (de forma mais ampla). Ataíde e Pinho (2013) reforçam a importância da habilidade que se deve adquirir atualmente, em uma época marcada pelo surgimento e aperfeiçoamento de Novas Tecnologias de Comunicação e Informação (NTCl):

[...] requer do indivíduo uma formação que favoreça atuar com desenvoltura nos diversos contextos tecnológicos. Assim, a educação precisa atender à emergência de uma sociedade que enfrenta diariamente o desafio de absorver os impactos advindos dos novos artefatos que surgem vertiginosamente. Ademais, se movimentar entre o real e o virtual é uma habilidade a mais que se espera do profissional egresso das escolas e universidades brasileiras (p. 68).

Araújo e Glotz (2009) contribuem elucidando o entendimento e a preocupação acerca da falta de letramento dos indivíduos da atualidade e que, como consequência, os deixa de certa maneira excluídos e marginalizados na esfera social, pois sem ter o domínio da leitura, escrita e talvez interpretação não 
acompanham e não "dialogam" com as tecnologias na medida em que caminham para avanços de diversas formas. Araújo e Glotz (2009, p. 2) ainda ponderam que:

O Brasil é um dos países que vem há anos se debatendo com este problema; a busca de alternativas teóricas e metodológicas para que estes indivíduos deixem de fazer parte do contingente de analfabetos e passem a ser indivíduos com domínio do mundo letrado é uma questão premente, uma vez que no nosso atual contexto - o de uma sociedade globalizada, competitiva, que cada vez exige mais saberes e competências de seus sujeitos - aqueles que não possuem esse domínio estão sendo cada vez mais escanteados, ingressando nas estatísticas de exclusão social.

Freitas (2010) frisa que o sistema de ensino está aparentemente obsoleto, considerando a forma de ensino aprendizagem que se baseia na escola e no livro. $O$ autor aponta que "[...] na rede informacional que envolve todos, misturam-se vários saberes e formas muito diversas de aprender, enquanto o sistema educativo ainda encontra-se todo organizado em torno da escola e do livro" (p. 341). Ainda para Freitas (2010) o letramento digital e contato com as tecnologias digitais proporcionam aos alunos a possibilidade de estenderem seu raciocínio crítico para patamares superiores. De certo modo ganham em capacidade reflexiva:

Consideraram que os recursos on-line, ao serem introduzidos na dinâmica do ensino presencial, ampliam o espaço da sala de aula e os alunos se sentem envolvidos em buscar outras fontes e recursos para alimentar as discussões nos fóruns. Destacaram as possibilidades que esse novo ambiente traz para o processo de ensino e aprendizagem, prolongando a reflexão e o desenvolvimento da capacidade argumentativa dos seus usuários (FREITAS, 2010, p. 342-343).

Bedran (2016) destaca relevante aspecto que faz intersecção entre letramento e meios de comunicação virtuais. $O$ autor consegue construir uma reflexão sobre as formas anteriores e atuais de comunicação e ressalta que:

Diversos modos de comunicação tornam-se possíveis no ciberespaço diante de recursos da Internet que permitem às pessoas interagirem de maneira recíproca, assíncrona e a distância particularidades inexistentes em outras formas de comunicação até então existentes, como o correio, por exemplo, conforme aponta o autor, e, principalmente, de maneira síncrona, quando pensamos mais contemporaneamente na (re)organização de uma sociedade, a qual se dá a partir da utilização de recursos de áudio e vídeo para e na realização do processo de comunicação. Ao serem responsáveis por novas formas de comunicação, essas inovações tecnológicas necessariamente também contribuem com as novas formas de atuar, de se manifestar, de construir e de se posicionar em sociedade, tendo em vista a particularidade de cada instrumento, aplicativo, plataforma e/ou ambiente tecnológico utilizado, que auxiliam na configuração e delineação dessas diversas práticas (BEDRAN, 2016, p. 226). 
Para Bedran (2016), no contexto de um ambiente organizacional escolar um dos atores envolvidos na vivência prática no processo ensino-aprendizagem - 0 professor -, precisa voltar sua atenção para o letramento digital dele mesmo, pois não basta ter capacidade técnica para dominar as diversas ferramentas que a tecnologia coloca à disposição, mas também "[...] exige uma formação reflexiva, questionadora e também produtora diante da tecnologia da informação" (p. 231).

Diante das várias ferramentas disponíveis para ler e escrever, os
modos de letramento passaram a configurar um novo domínio de uso
da palavra, constituindo o espaço digital. Essas ferramentas podem
ser encontradas nos mais diversos "espaços" de uso do computador
e da Internet por meio de várias atividades, como escrever e-mails,
fazer transferências bancárias, recadastrar CPF, namorar no chat
aberto, manter um perfil no facebook etc., concretizando certa
mudança no espaço da escrita da página para a tela (NUNES et al.,
2015, p. 122-123).

Ataíde e Pinho (2013) pontuam que, a partir da investigação que realizaram, os estudantes não têm preparo suficiente para lidar com o computador e seus periféricos e, em função disso, não são considerados alfabetizados tecnologicamente, pois "[...] o letramento digital é, ou chega a ser, uma prática indiferente para os mesmos, o que atua desfavoravelmente no sentido da aquisição e apropriação dos conteúdos que são postados on-line" (p. 77). Diante do contexto apresentado, o presente trabalho teve como objetivo principal investigar o letramento digital de estudantes de cursos de várias licenciaturas que participaram de editais do PIBID para o ano de 2016, na UFG-RC.

\section{MATERIAL E MÉTODOS}

Numa etapa anterior, que não é foco desse trabalho, foi desenvolvido um software para atender as demandas do PIBID/UFG-RC. O desenvolvimento deste software pautou-se na constatação de que havia a necessidade de um sistema de informação que trouxesse eficiência e eficácia, pois o processo de inscrição era realizado presencialmente e todos os documentos exigidos no edital entregues impressos.

O referido software foi projetado para ambiente web, pois dessa forma se torna acessível para a totalidade das pessoas envolvidas no processo. Após a conclusão do software, este foi colocado em funcionamento e disponibilizado para o público-alvo, juntamente com materiais orientadores de uso (vídeo expositivo demonstrando o passo a passo; manual de instruções em texto digital).

$\mathrm{O}$ instrumento utilizado para coleta das informações sobre o letramento digital de estudantes, tendo como foco o uso do sistema mencionado anteriormente, foi o questionário, inserido como formulário do Google Forms (GOOGLE, 2017). A escolha se deu por ser uma ferramenta disponibilizada gratuitamente e que pode ser aplicada on-line. O contato com os participantes, assim como o envio do link para preenchimento do questionário ocorreu por e-mail, utilizando o endereço que cadastraram no sistema de inscrições. Para a análise dos dados foi usada uma perspectiva quanti-qualitativa.

Depois de colocado em funcionamento o sistema on-line de inscrições do PIBID e finalizadas as etapas do edital, o questionário on-line foi enviado a todos os participantes e, no total, 20 responderam. 


\section{RESULTADOS E DISCUSSÃO}

Segundo a análise das respostas obtidas através dos questionários on-line, $95 \%$ das pessoas indicaram que frequentemente navegam na Internet (figura 1).

\section{Acesso à Internet}

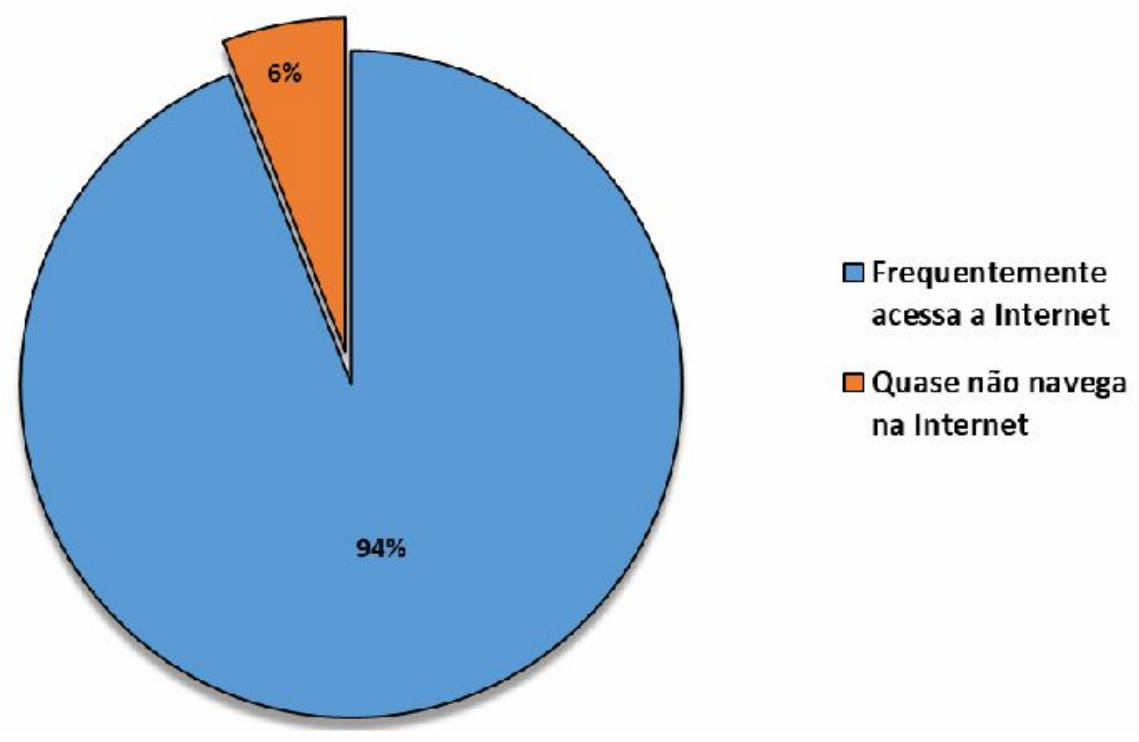

FIGURA 1: Acesso à Internet (elaborada pelos autores).

Esta pergunta foi colocada no questionário como o objetivo de saber se as pessoas que participaram do estudo têm o hábito de acessar a Internet, pois ao fazer isso elas estão navegando em sites diversos e em aplicativos que solicitam/exigem ler e escrever conteúdos diversos e, de forma geral, interpretar, participar, interagir socialmente se comunicando com outras pessoas através das TICs, aspectos relevantes do contato com essas tecnologias (GARCIA; SOUSA, 2011; KIRCHOF, 2016).

Em relação à utilização da internet (figura 2), 94\% dos participantes informaram utilizá-la para navegar em redes sociais. Sabe-se que estas redes solicitam um cadastro prévio com confirmação/ativação das credenciais de acesso para só assim poderem continuar a navegar. Assim sendo, como no cadastramento no sistema on-line do PIBID da UFG-RC o procedimento é semelhante, em tese, essa experiência já colaboraria para o êxito nas inscrições. 


\section{O que fazem na Internet}

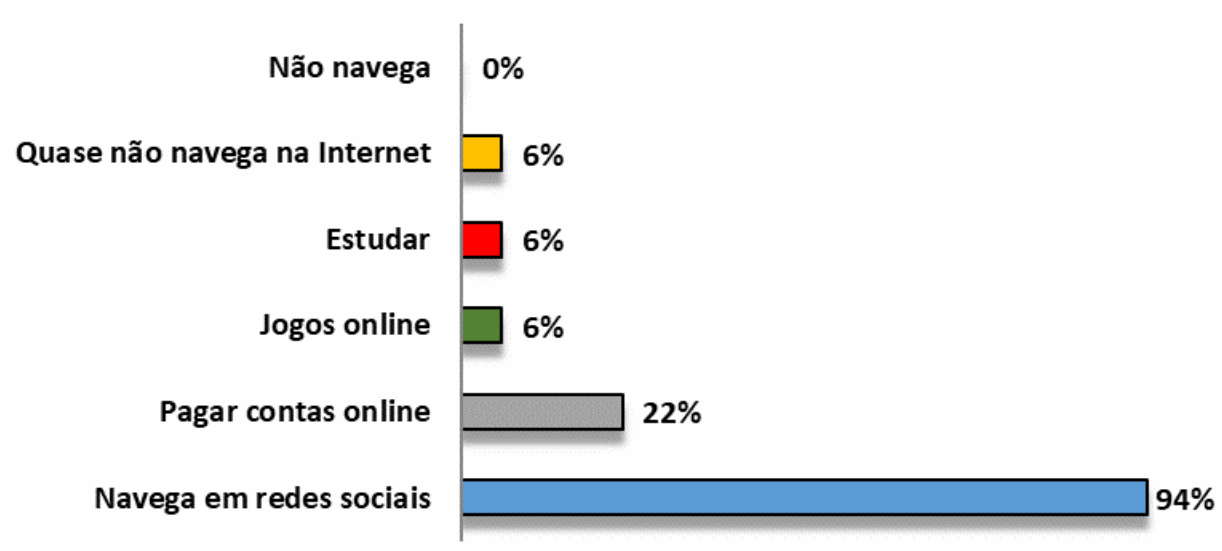

FIGURA 2: O que fazem na Internet (elaborada pelos autores).

Sobre a navegação no sistema (figura 3), 56\% dos participantes afirmaram que tiveram pouca dificuldade em acessar e navegar no sistema on-line do PIBID da UFG-RC. Isso evidencia que o sistema ora implementado, se mostrou capaz de conduzir um processo interativo com o objetivo de visualizar editais abertos, cadastrar-se e acompanhar inscrição(ões) nos subprojetos do programa PIBID da UFG-RC.

\section{Escala de dificuldade ao navegar no sistema online}

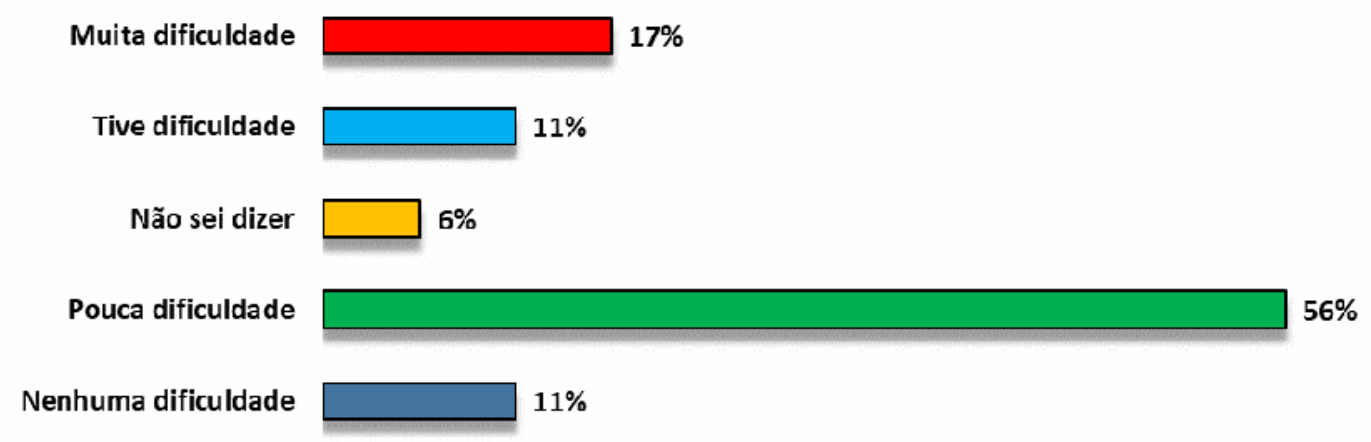

FIGURA 3: Escala de dificuldade ao navegar no sistema (elaborada pelos autores).

Ao contrário dos resultados de Ataíde e Pinho (2013), o público investigado apresentou habilidade suficiente para além de ler e escrever, interagir e participar do processo on-line como um todo. Sobre as informações disponibilizadas no sistema on-line (figura 4), 6\% consideraram que houve excesso de informação, $44 \%$ informaram que haviam informações suficientes, $22 \%$ não sabem dizer, $28 \%$ afirmaram ter pouca informação e 0\% consideraram ter nenhuma informação. 


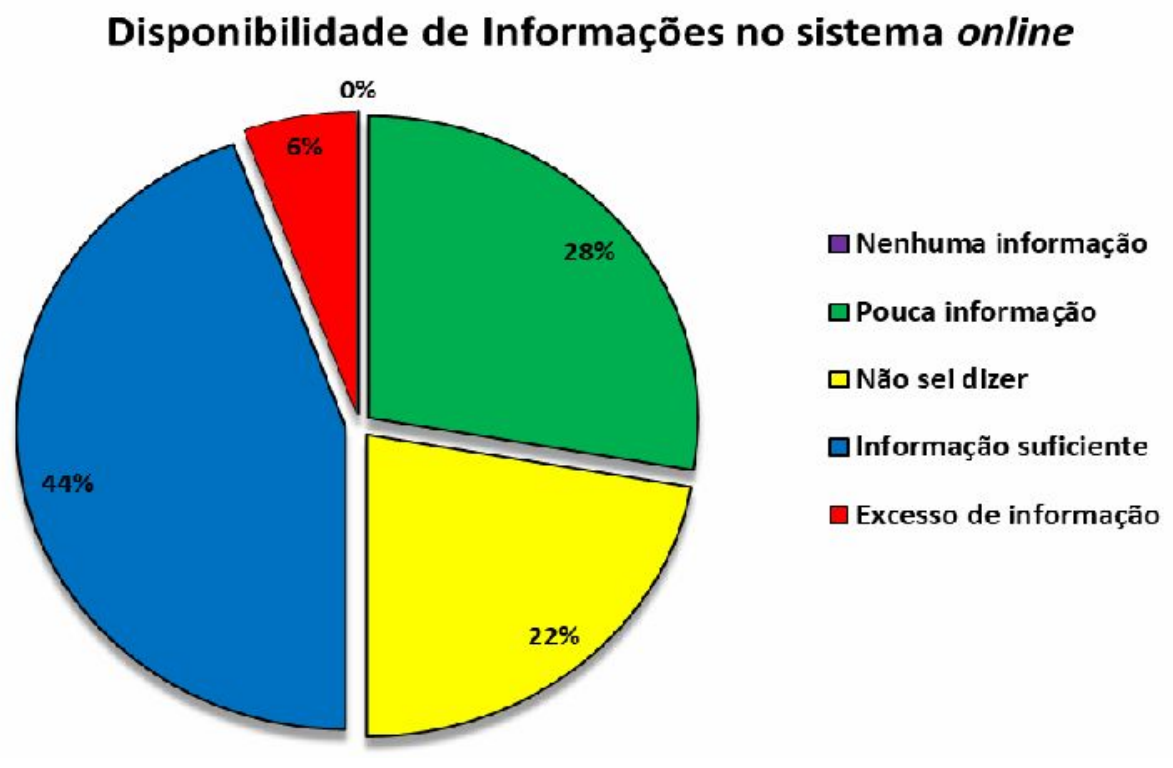

FIGURA 4: Disponibilidade de informações no sistema (elaborada pelos autores).

Ainda da figura 4 , verifica-se que $28 \%$ dos participantes afirmaram ter pouca informação disponibilizada, visto que várias informações foram oferecidas com instruções através de variados meios, ficou a compreensão de que nem todos tiveram a iniciativa de procurar e acessar as informações. Esse entendimento é confirmado com a análise sobre a visualização das informações (figura 5).

\section{Leitura das informações disponibilizadas}

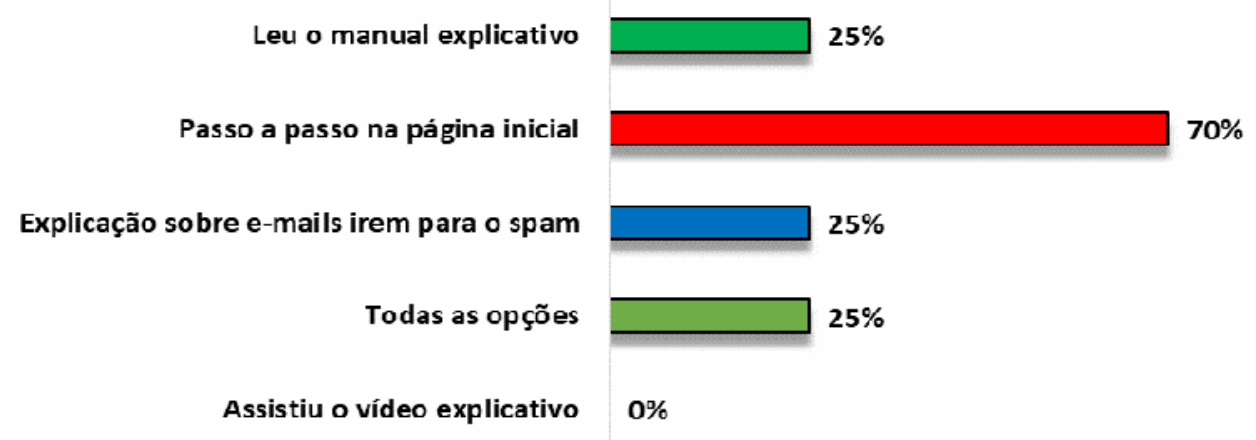

FIGURA 5: Leitura das informações disponibilizadas (elaborada pelos autores)

$\mathrm{Na}$ figura 5 , verifica-se que apenas $25 \%$ dos participantes acessaram e leram o manual explicativo, e nenhum (0\%) dos participantes acessou o vídeo explicativo. Esses valores revelam que algumas pessoas poderiam estar extremamente familiarizadas com sistemas on-line, dispensando a necessidade de leitura das orientações ou faltou procurar compreender o ambiente em sua "[...] totalidade reflexiva" (TIBURZIO, 2014). Os participantes também foram questionados sobre a relevância das informações disponibilizadas (figura 6). 


\section{Sobre as informações disponibilizadas}

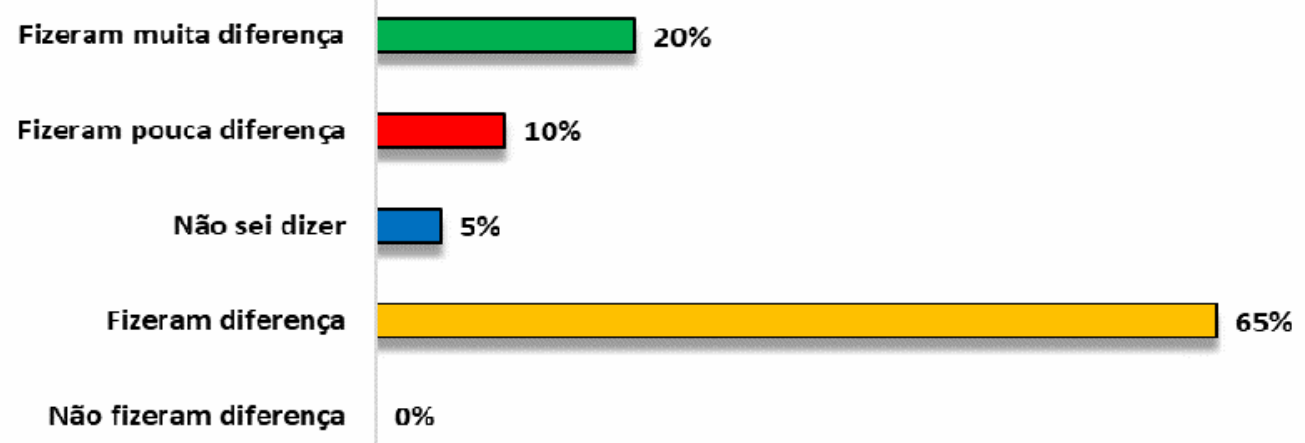

FIGURA 6: Sobre as informações disponibilizadas (elaborada pelos autores).

Sobre o grau de relevância das informações, os participantes dessa pesquisa, (65\%) responderam que as informações fizeram diferença no decorrer do processo, para $20 \%$ as informações fizeram muita diferença, enquanto que para $10 \%$ as informações fizeram pouca diferença e $5 \%$ não souberam dizer.

Ainda sobre a relevância das informações disponibilizadas, havia no formulário (instrumento e pesquisa) um campo/espaço para a justificativa da resposta, caso julgassem pertinente, campo esse que foi utilizado por apenas $10 \%$ dos participantes. Dentre as respostas registradas, deve-se destacar que foram diametralmente opostas, sendo a primeira a seguinte: "Foi importante" e a segunda "As informações estavam bagunçadas, não direcionava o caminho certo a seguir, e anexar os documentos estava difícil". Dando a entender que os participantes podem ter pouco ou nenhum domínio/contato com as TICs.

Segundo Nunes et al., (2015) os meios digitais é algo "novo". Deve-se entender o termo novo como algo que está em transição, de uma forma para outra, da folha de papel para a tela digital dos dispositivos eletrônicos. Os resultados deste estudo vão ao encontro deste aspecto apontado pelos autores, pois demonstraram que os licenciandos envolvidos no processo, ao operarem o sistema por meios digitais encontram dificuldade(s) no manuseio do mesmo. No contexto dos resultados, vários aspectos foram considerados, identificados e avaliados como, por exemplo, a dificuldade em operar o sistema on-line.

Xavier $(2017$, p. 2) ressalta que o letramento digital é a habilidade de lidar com a leitura e escrita, porém, no ambiente digital. Os atores envolvidos nos processos de leitura e escrita digitais são levados a adaptar-se às "novas" formas de linguagem, através do diálogo por voz ou vídeo e pelos "códigos e sinais verbais e não-verbais, como imagens e desenhos", presentes e acessíveis na Internet. Portanto, de acordo com o que foi descrito em seções anteriores, sobre o material disponibilizado aos participantes, é importante ressaltar que este material contém imagens - prints de tela - para melhor explicar aos participantes o que e como deveriam manusear o sistema on-line.

Freitas (2010) ressalta importante aspecto acerca do processo de ensino e aprendizagem que ainda se encontra principalmente organizado ou baseado na escola e no livro. O autor também salienta que o contato com as novas formas de comunicação digital e, portanto, letramento digital, leva os atores envolvidos com os mecanismos de leitura e escrita a um patamar mais amplo, e em decorrência disso 
leva os atores a expandirem a capacidade argumentativa pelo fato de terem acesso a mais informações em um tempo menor por meio da Internet. Diante disso, importa dizer que toda mudança traz consigo resistência por parte dos envolvidos, na maioria das vezes. Isto posto, considerando a opinião do autor e a crescente expansão dos meios digitais no âmbito acadêmico e também no âmbito de letramento digital, é pertinente pontuar que, por mais que os resultados tenham apresentado que os envolvidos tiveram dificuldade no manuseio do sistema on-line, ressalta-se que diversos instrumentos informacionais/instrutivos foram disponibilizados em meios digitais para que os licenciandos acessassem e se instruíssem para que tivessem o mínimo de dificuldade ou nenhuma dificuldade.

\section{CONCLUSÃO}

Retornando ao objetivo pretendido neste trabalho, que foi o de investigar o letramento digital de estudantes licenciados que participaram de editais do PIBID para o ano de 2016, na Universidade Federal de Goiás - Regional Catalão, os resultados do estudo revelaram que os participantes dessa pesquisa não possuíam ampla compreensão da leitura e escrita das informações contidas no sistema de inscrições on-line, mesmo que $85 \%$ tenha respondido que as informações foram relevantes. Em síntese, a existência e a acessibilidade das informações não garante que estas serão acessadas e lidas e tão pouco consequentemente compreendidas.

É preciso frisar que $94 \%$ dos participantes navegam na Internet e o mesmo percentual passa este tempo em redes sociais, o que promove o contato com recursos, tais como conversas em tempo real em salas de bate-papo, visualização de imagens e vídeos, enfim, a proximidade constante com algumas das ações necessárias em sistemas on-line, como o que integrou a presente pesquisa.

Contudo, notamos, que esse conhecimento em relação ao navegar pela internet, não garantiu a facilidade de acesso e utilização do sistema de inscrição, afinal $28 \%$ apresentou (muita) dificuldade, o que aponta para a necessidade de formação para o letramento digital.

Diante dos dados e resultados coletados, em que os participantes são estudantes universitários, pode-se ainda, ter a falsa percepção de que todos os participantes possuem um bom nível de letramento digital, mas os resultados apontaram para a urgente necessidade de ações para democratizar o acesso às ferramentas nele presentes. Caso contrário, a oferta de novas oportunidades de bolsas de programas estudantis e/ou assistências não estarão acessíveis a todos, não por falta do perfil/critérios acadêmicos exigidos para a implementação da bolsa, mas pela dificuldade de compreensão e utilização dos meios tecnológicos utilizados para participar/pleitear essas oportunidades.

\section{REFERÊNCIAS}

ARAÚJO, V. D. L.; GLOTZ, R. E. O. O letramento digital enquanto instrumento de inclusão social e democratização do conhecimento: desafios atuais. Revista Científica de Educação a Distância, v. 2, n. 1, p. 1-26, jun. 2009. Disponível em: $<$ http://periodicos.unimesvirtual.com.br/index.php?journal=paideia\&page=article \&op= view\&path[] $=85 \&$ path[] $=50>$.

ATAIDE, D. M. S.; PINHO, M. J. Letramento digital e alfabetização tecnológica: reflexões a partir de um estudo com alunos do PARFOR. Educação, Formação \& Tecnologias, v. 6, n. 2, p. 68-79, jul./dez. 2013. Disponível em: 
$<$ https://eft.educom.pt/index.php/eft/article/view/277/185>.

BEDRAN, P. F. Letramento digital e a formação do professor de língua na contemporaneidade. Entre Línguas, v. 2, n. 2, p. 225-247, jul./dez. 2016. Disponível em: <https://seer.fclar.unesp.br/entrelinguas/article/download/8614/5932>.

BORGES, F. G. B. A construção de uma metodologia para o letramento digital. Raído, v. 11, n. 25, p. 67-77 jan./jun. 2017. Disponível em: $<$ http://periodicoscientificos.ufmt.br/ojs/index.php/polifonia/issue/download/421/pdf_5 $>$.

FREITAS, M. T. Letramento digital e formação de professores. Educação em Revista, v. 26, n. 03, p. 335-352, dez. 2010. Disponível em: <http://www.scielo.br/pdf/edur/v26n3/v26n3a17>.

GARCIA, J. C. R.; SOUSA, M. R. F. Cultura digital: odisseia da tecnologia e da ciência. Em Questão, v. 17, n. 2, p. 77-90, jul./dez. 2011. Disponível em: < http://seer.ufrgs.br/index.php/EmQuestao/article/view/22252/14320>

GOOGLE. Google forms. Disponível em: <https://www.google.com/forms/about/>. Acesso em: 18 dez. 2017.

KIRCHOF, E. R. Como ler os textos literários na era da cultura digital? Estudos de literatura brasileira contemporânea, n. 47, p. 203-228, jan./jun. 2016. Disponível em: <http://www.scielo.br/pdf/elbc/n47/2316-4018-elbc-47-00203.pdf>

MENDONÇA, T. C.; VARVAKIS, G. Análise do uso da informação para tomada de decisão gerencial em gestão de pessoas: estudo de caso em uma instituição bancária. Perspectivas em Ciência da Informação, v. 23, n. 1, p. 104-119, abr. 2018.

Disponível

em:

<http://portaldeperiodicos.eci.ufmg.br/index.php/pci/article/view/2417/2059>.

NUNES, E. L.; DIAS, J. J. F.; LIMA, R. P. Letramento digital: estudo de caso sobre a formação para o conhecimento de informática através do curso UNIFAPDIGITAL. PRACS: Revista Eletrônica de Humanidades do Curso de Ciências Sociais da UNIFAP, v. 8, n. 2, p. 119-136, jul./dez. 2015. Disponível em: $<$ https://periodicos.unifap.br/index.php/pracs/article/view/1875>.

SOUZA, V. V. S. Virtual Learning Environments in the Light of the Complexity Paradigm: Interface, Affordances and Equifinality. Revista Brasileira de Linguística Aplicada, v. 13, n. 2, p. 577-601, 2013. Disponível em: < http://www.scielo.br/pdf/rbla/v13n2/aop0713.pdf>. Doi: $\quad$ 10.1590/S198463982013005000007.

TIBURZIO, G. V. Interação e letramento digital: implicações teóricas a serem consideradas em análises de fóruns virtuais de aprendizagem. Revista Memento, v. 5, n. 1, p. 1-12, jan.jun. 2014. Disponível em: <https://dialnet.unirioja.es/descarga/articulo/4812450.pdf>

VIEIRA, E. A percepção da informação e da sua relevância no cenário institucional: sob a perspectiva de gestores e líderes. Cadernos EBAPE.BR, v. 12, n. esp., p. ENCICLOPÉDIA BIOSFERA, Centro Científico Conhecer - Goiânia, v. 15 n.27; p.1492 2018 
533-552,

ago.

2014.

Disponível

em

$<$ http://www.scielo.br/scielo.php?script=sci_arttext\&pid=S1679-

$39512014000700010 \&$ Ing=pt\&nrm=iso>. Doi: $10.1590 / 1679-39519085$.

XAVIER, A. C. S. Letramento digital e ensino. Disponível em: <http://www.nehte.com.br/artigos/Letramento-Digital-Xavier.pdf>. Acesso em: 18 dez. 2017. 